\title{
INTERNET COMO ALTERNATIVA PARA O ENGAJAMENTO \\ CÍVICO - \\ REFLEXÕES SOBRE O CASO DAS ONGS
}

\author{
THE INTERNET AS AN ALTERNATIVE FOR ACHIEVING CIVIC \\ ENGAGEMENT - \\ REFLECTIONS BASED ON EXPERIENCES OF NGOS
}

\author{
LA INTERNET COMO UN MEDIO PARA ALCANZAR EL COMPROMISO \\ CÍVICO - \\ REFLEXIONES SOBRE EL CASO DE LAS ONGS
}

\author{
Raquel Gomes de Oliveira \\ Doutora, Universidade Federal da Bahia \\ raqgomes@yahoo.com.br \\ Luciana de Fátima Pinto Santos \\ Mestranda, Universidade Federal da Bahia \\ llucipinto@yahoo.com.br
}

\section{Resumo}

Este artigo se destina a refletir sobre as Organizações Não Governamentais e a utilização da Internet como alternativa para o fomento do engajamento cívico. Para tanto, conceitualiza-se sociedade civil e as ONGs, como organização incluente desta esfera, e compreende-se a expressão engajamento cívico em conceitos que se complementam. Para a pesquisa empírica utilizou-se como recorte as organizações que são associadas à Associação Brasileira de ONGs, no estado da Bahia. De forma geral, a pesquisa permitiu sinalizar que ouso da Internet pelas ONGs estudadas ainda é uma alternativa pouco profícua para fomentar o engajamento cívico.

Palavras-Chave: ONGs. Internet. Engajamento cívico.

\section{Abstract}

This article is intended to reflect on non-governmental organizations and the use of the Internet as an alternative to the promotion of civic engagement. For this end, conceptualize civil society and NGOs, as an organization owned this sphere, and we understand the term civic engagement in concepts that complement each other. For the empirical research was used as study object the organizations that are associated with the Brazilian Association of NGOs, in the state of Bahia. Overall, the survey signal that allowed the Internet by NGOs dare studied is still a little fruitful alternative to foster civic engagement.

Keywords: NGOs. Internet. Civic engagement..

Esta obra está licenciada sob uma Licença Creative Commons 


\section{Resumen}

Este artículo se propone a hacer una reflexión sobre las Organizaciones NonGubernamentales y la utilización de la Internet como alternativa para la promoción del compromiso cívico. Por lo tanto, se consideran la sociedad civil y las ONGs como organismos incluyentes y se comprende la expresión compromiso cívico en conceptos complementarios a ellos. Para la investigación empírica se utilizó una amuestra de organizaciones socias de la Asociación brasileiras de ONGs en el estado de Bahia. De manera general, la investigación permite señalar que la utilización de la Internet por las ONGs estudiadas es todavía una alternativa poco proficua para la promoción del compromiso cívico.

Palabras-Claves: ONGs. Internet. Compomiso Cívico.

\section{INTRODUÇÃO}

A comunicação desenvolvida pelas ONGs atualmente ocupa maior centralidade na ação institucional e se alia cada vez mais às crescentes possibilidades de interação social, trazidas pelas Tecnologias de Informação e Comunicação (TIC’s). Em um campo de produção de informações profícuo, como o das instituições não governamentais, partimos da idea que a utilização da Internet pode contribuir para um maior engajamento cívico para com as causas defendidas por tais entidades. Á medida que seus discursos, valores e crenças são disponibilizados nos ambientes virtuais, e, dentre outros elementos, são fomentadas a participação e a capacidade de disseminação das práticas institucionais e temas trabalhados, contribuindo para a formação da opinião pública.

Questiona-se, assim, se a utilização de espaços na Internet por ONGs pode significar um avanço nos processos de engajamento cívico fomentados por tais organizações?

Essa questão orienta as motivações para as reflexões presentes nesse artigo, que objetiva, em uma primeira abordagem, perceber como são apresentados os ambientes de Internet criados pelas ONGs, observando elementos que possam apontar perspectivas de um maior engajamento cívico. Para isso utilizamos como recorte as organizações que são associadas à Associação Brasileira de ONGs - ABONG, no estado da Bahia, totalizadas em 28 entidades, de acordo com o site da Associação. ${ }^{1}$

Do ponto de vista metodológico trabalhamos com uma breve revisão bibliográfica sobre os conceitos de sociedade civil, destacando a idéia de ONGs, além do conceito de engajamento cívico. Para a pesquisa empírica foi elaborado um levantamento sobre a presença

\footnotetext{
${ }^{1}$ www.abong.org.br
} 
das ONGs na Internet, tendo-se como base principal os sites institucionais, e a partir dele, catalogamos o direcionamento para outros espaços tais como redes sociais, fóruns e blogs. Do ponto de vista de cada site, além de espaços que possam fomentar a participação, observou-se também a natureza do conteúdo disponibilizado.

\section{ONG, UM ÂMBITO DA SOCIEDADE CIVIL EM BUSCA DE ENGAJAMENTO CÍVICO}

O termo sociedade civil, seguramente é um dos conceitos da teoria política clássica mais usado no discurso social e político contemporâneo. Uma série de classificações tem sido feitas por vários autores ${ }^{2}$ que, no decorrer da história, trabalharam e contribuíram para o desenvolvimento de tal conceito. Inicialmente, o termo sociedade civil era entendido como sinônimo de Estado, como uma comunidade política enraizada nos princípios da cidadania. A preocupação dos autores era de analisar as condições sob as quais os seres humanos poderiam escapar do Estado de natureza e entrar em uma forma contratual de governo baseada na regra da lei, isto é, em uma sociedade civil.

Novas perspectivas do conceito surgiram e pode-se dizer que algumas das matrizes teóricas mais relevantes à conceituação da sociedade civil para análises atuais são as neotoquevilleana, neoliberal, habermasiana e gramsciana, originando uma diversidade de significados muitas vezes contraditórios. Para perceber a complexidade do entendimento de sociedade civil, nos últimos anos, com a intensificação dos processos de globalização passam a existir ainda, as teorizações acerca da existência de uma sociedade civil internacional ou global $^{3}$.

A definição de sociedade civil, aqui é trabalhada com o objetivo de situar, em um campo conceitual mais amplo as Organizações Não Governamentais, as chamadas ONGs, objeto mais específico de nosso estudo. Todas as matrizes teóricas trazem contribuições e discussões importantes para o termo sociedade civil, entretanto duas delas focam mais ao que concerne as ONGs.

A matriz teórica habermasiana, por entender a contribuição e o ganho dos movimentos sociais em termos da institucionalização dos direitos (Arato e Cohen, 1994, p.176), fornece

\footnotetext{
${ }^{2}$ Desde sua recuperação no período medieval através da tradução da Política de Aristóteles (koinonia politike para societas civilis) por William von Moerbeke, o conceito tem sido reformulado por quase todos os filósofos políticos ocidentais significativos, passando por Hobbes, Locke, Rousseau, Ferguson, Smith, Kant, Hegel, Tocqueville, Marx, Gramsci.

${ }^{3}$ Ver Lipschutz, 1992; Kenny, 2003; Peterson, 1992; Cox, 1999; Colás, 2002; Shaw, 1992; Ghils, 1992; Keane, 2003 e Kaldor, 2003, para alguns exemplos.
} 
um relevante aporte teórico na medida em que identifica a importância desses movimentos para além da sua mera existência e manifestação. Há a consideração do valor destes no processo dialético das conquistas históricas dos setores mais marginalizados expressos na realização das demandas de tais movimentos. A crítica a esta matriz, como também a de neotoquevilleana e neoliberal, é que não há luta pela transformação do poder estatal e/ou do mercado, uma vez que estes são tidos como inatingíveis; o que se busca é o poder que está ao alcance do subalterno, do cidadão comum, criado nas associações e organizações comunitárias. Portanto, atuam dentro, e muitas vezes a favor, da ordem capitalista.

Como aponta Pinheiro (1994) a superioridade da matriz de Gramsci assinala para a necessidade de uma perspectiva diferente que trata não apenas de entender a realidade, mas também de transformá-la. Assim, de maneira mais específica, a sociedade civil é “o conjunto de organismos designados vulgarmente como ‘privados’(...)” (Gramsci, 2001 p. 20), formada pelas organizações responsáveis tanto pela elaboração quanto pela difusão de ideologias, envolvendo assim o sistema escolar, as igrejas, os sindicatos, os partidos políticos, as organizações profissionais, a organização material da cultura (que se dá pelos jornais, revistas, editoras, meios de comunicação de massa), etc. Em suma, os organismos sociais coletivos voluntários e relativamente autônomos, considerados como uma das esferas principais do Estado visto em seu sentido ampliado; a em face da sociedade política.

Assim, a escolha pelo pensamento de Gramsci se da por sua introdução a distinção de poder entre sociedade civil e sociedade política. Essa diferenciação traz a luz a relativa independência, e complexidade com relação à base econômica, das instituições, das organizações, e da ideologia pelas quais é promulgado o poder de uma classe, além de servir para aclarar a relação dialética entre coerção e consenso, ditadura e hegemonia, que serve de base e expressão para o poder de uma classe.

Ainda assim é preciso estar atento, como aponta Dias, citado por Ribeiro (2000), quando afirma que "um dos principais erros no modo de pensar a Sociedade Civil é fazê-lo como articulação indistinta de instituições, expressão de interesses universais, não contraditórias e classistas” (Ribeiro, 2000, p.15). Neste sentido, é em um segmento mais específico da sociedade civil que se nota a presença das ONGs, objeto específico da reflexão aqui apresentada.

A expressão ONGs teve seu reconhecimento no cenário mundial no final da década de 1950, a partir da Organização das Nações Unidas (ONU), que de acordo com Menescal (1996) adotou o termo para mencionar entidades que atuavam em nível supra e internacional, e que não foram estabelecidas por acordos internacionais. 
Sherren-Warren, citada por Gohn (2003), aponta as ONGs como entidades formais, privadas, porém com fins públicos e sem fins lucrativos. Para a autora, tratam-se de instituições autônomas, que realizam mediações de caráter educacional, político e técnico para populações específicas, expandindo o poder de participação destas, na busca por desencadear transformações sociais ao nível micro ou macro.

Seja na perspectiva do fortalecimento da democracia, seja num aspecto mais micro da publicização das ações institucionais, a comunicação é a mola propulsora para a promoção de um processo de engajamento cívico.

No artigo What Do We Mean By "Civic Engagement"? os autores Goggin e Adler (2005) nos alertam que como o termo engajamento cívico é definido depende da perspectiva e os interesses de quem o define, e acrescenta que impressiona a vasta gama de definições para tal conceito. Duas formas interessam particularmente neste artigo. Engajamento cívico como envolvimento político e engajamento cívico como mudança social.

Para Bernie Ronan (apud Goggin e Adler, 2005), que foca nas dimensões políticas e coletivas do termo referindo-se ao histórico das palavras: a palavra latina Civis encontrou seu caminho em duas palavras, cidade e cidadão. Engajamento cívico trata assim, de redescobrir a política, a vida da polis, a cidade onde homens e mulheres, falam e agem juntos, como cidadãos. A palavra cívica, quando ligada ao engajamento, implica trabalho que é feito publicamente e benefícios ao público, e é feito em conjunto com os outros.

A definição do Minnesota Vital Aging Network também faz uma explícita distinção entre as atividades de serviços e atividades cívicas e afirma que engajamento cívico deve incluir um componente de liderança pública e descreve a participação do cidadão nos assuntos cívicos, Serviço implica fazer por e cívico implica em fazer com. Serviço é sobre atender às necessidades das pessoas e cívico trataria mais sobre deliberações destinadas às questões públicas. Assim engajamento cívico envolve a participação ativa e de liderança na vida pública.

Já o engajamento cívico como mudança social, definido por David Crowley (ibidem) enfoca o elemento de mudança social inerente na participação cívica: engajamento cívico descreve como um cidadão ativo participa na vida da comunidade, a fim de ajudar a moldar o seu futuro. Em última análise, engajamento cívico tem que incluir as dimensões de mudança social.

Também cabe pensar no termo de forma mais simples e abrangente. Por exemplo, Michael Della Carpini (ibidem) faz questão de afirmar que sociedade civil abarca uma ampla gama de atividades, de diferentes tipos e que são ações individuais e coletivas destinadas a 
identificar e abordar questões de interesse público, podendo assumir muitas formas, desde voluntarismo individual ao envolvimento de uma organização com a participação eleitoral. Pode incluir esforços para resolver uma questão diretamente, trabalhar com outras pessoas em uma comunidade para resolver problemas, ou interagir com as intituições democráticas. E cita também que engajamento cívico engloba uma gama de atividade específicas, tais como trabalhar em uma cozinha servindo uma associação de bairro, escrevendo uma carta para um funcionário eleito ou votando.

Corroborando com essa última definição entendem-se duas formas de engajamento cívico, que podem ser complementares se pensamos em uma ideia mais ampla de participação, como pontua Rennó:

A primeira forma de engajamento em ação coletiva analisada é a participação em associações de âmbito nacional, com claros objetivos políticos e voltadas para a defesa de interesses específicos: partidos políticos e sindicatos. (...) A segunda variável dependente analisada indica a participação em grupos sociais locais, como grupos de mães, associações de bairro e grupos de igreja. (RENNÓ, 2003, p. 2)

As organizações não governamentais, portanto, enquanto um segmento da sociedade civil demanda para existirem, não apenas para o publico ou causa que defendem, que esse engajamento cívico se dê, em um âmbito maior da sociedade, a fim de que suas ações ampliem seu espectro de abrangência.

Dentre os mecanismos comumente utilizados pelas ONGs para promover essas relações com a sociedade, estão as chamadas ações comunicativas, as quais Carvalho (2010), citando Torres, acentua como um processo no qual "as pessoas devem assegurar-se de que podem entender, confiar, acreditar e concordar com o que é dito (Torres apud Carvalho, 2010, p.4).

Já para Armani (1999) a comunicação está inscrita no campo do desenvolvimento institucional das ONGs. O autor reflete que é nesse campo que reside a força motriz produtora de instrumentos específicos de articulação, comunicação e representação, contribuindo para a maior projeção pública das ONGs.

É nesse contexto que a comunicação em todas as suas dimensões passa a ser inserida com maior força nos processos de gestão das ONGs, garantindo presença nos planejamentos institucionais e sendo considerada quando da realização de monitoramentos e avaliações periódicas de projetos e programas.

Como defende Bennet (2000), este é um importante momento para os estudiosos de comunicação desenvolverem concepções de mudanças social em conjunto com a forma como 
as pessoas em diferentes grupos culturais definem suas relações com o governo e, mais amplamente, a sociedade civil.

\section{A importância da comunicação das ONGs para o engajamento cívico na Internet}

Com as mudanças históricas, sociais, políticas e culturais pelas quais passou e vem passando a sociedade no Brasil, em particular desde a reabertura democrática, em meados da década de 1980, entende-se que a atuação de ONGs tem cada vez mais necessidade de ampliar articulação, difundir suas causas e conquistar, consequentemente adesão da sociedade, como mecanismo fundamental para que se atinjam os resultados a que se propõem, o que só é possível em consonância com um processo de disseminação de informação mais amplo. Esse processo pode ser incrementado pelas práticas de comunicação, conforme aponta Gohn (2003), quando afirma que, na atualidade as ONGs intervém por meio de redes sociais, locais, regionais, nacionais e internacionais, e utilizam-se muito de novos meios de comunicação e informação. Por isso, exercitam a criação e o desenvolvimento de novos saberes que advém dessa comunicabilidade.

Um dos relevantes desafios lançados à comunicação das ONGs é a necessidade de se revelar publicamente de forma clara, enquanto segmento da sociedade civil, conforme afirma Menezes (2005). Essa visibilidade está ligada às ações desenvolvidas, de forma que os próprios resultados atingidos configuram-se como um importante elemento de mobilização social e sensibilização da opinião pública.

De acordo com Ribeiro (2004), a comunicação favorece a mobilização de recursos materiais e simbólicos ligados à transformação social, promovendo novas e complementares formas de produção de informações, que, podem significar o pensar institucional sobre suas práticas e o conseqüente desenvolvimento de conteúdos a serem disseminados, a exemplos de: vídeos, publicações, spots para rádio, slides, folders, banners, utilizando-se de meios como: wesites, blogs, material impresso, etc.

Com o advento das novas Tecnologias de Informação e Comunicação, uma nova perspectiva se insere de forma contundente no cotidiano e nas práticas de comunicação das ONGs: a Internet, que passa, a partir dos anos 1990, a dialogar com outros produtos e estratégias de comunicação adotadas pelas organizações.

Machado (2007) reflete que a Internet tornou-se, atualmente, um importante instrumento de articulação e comunicação das ONGs, movimentos sociais, ou mesmo grupos de cidadãos. Para o autor, a relevância da Internet em tais espaços pode decorrer, também, da 
possibilidade de comunicação rápida, barata e de grande alcance. Nesse sentido, ainda afirma que a rede se converteu em um espaço público determinante para o fortalecimento das demandas dos atores sociais, para ampliação do alcance de suas ações, e no desenvolvimento de estratégias de luta mais eficazes, favorecendo assim o engajamento cívico.

Bimber (2000a) nos alerta que engajamento cívico pode estar entre os fenômenos sociais e políticos sujeitos a mudanças sob a influência da revolução da informação, associada á Internet. Uma forma de saber sobre essa possibilidade é avaliar em que medida os aspectos mais importantes de engajamento cívico parece sensível a mudanças no custo ou distribuição de informação e comunicação. Engajamento cívico tem muitas características que poderiam concebivelmente ser sensíveis ás mudanças nas propriedades da informação e da comunicação: seus níveis globais ou extensão, a sua estrutura, suas qualidade normativas ou propriedades, e os assuntos e questões que despertam.

Por um lado pode-se pensar na Internet devido às suas características estruturais e circunstanciais, como alternativa para insuflar o engajamento, de indivíduos e grupos marginalizados. Porém muitos autores defendem a hipótese do reforço, que propõe que os recursos da internet seriam utilizados principalmente para expandir as chances de participação daqueles que já estariam previamente engajados (NORRIS, 2000, p. 7; 2003, p. 43; SCHEUFELE e NISBER, 2002, p. 69).

Dentre algumas experiências apresentadas de forma exitosa no que se refere ao uso da Internet pelas ONGs, Lopes (2005) lembra a campanha virtual contra a discriminação racial, desenvolvida em 2005 pelo Instituto Brasileiro de Análises Sociais e Econômicas (IBASE), denominada: “Mande um cartão vermelho para o racismo" 4 , que consistiu no envio de cartas virtuais para a Federação Internacional de Futebol, União das Associações Européias de Futebol (UEFA), entre outras instituições de naturezas afins, exigindo medidas eficazes contra o racismo nos campos de futebol, principalmente na Espanha.

Sabe-se também que muitas iniciativas na Internet não cumprem as expectativas esperadas, se perdendo na vastidão no universo virtual, não causando nem engajamento, nem reforço. O que se pretende é pensar as possibilidades da Internet como alternativa de engajamento para as ONGS. Desta maneira, os novos espaços favorecidos pelas TICs são cada vez mais apropriados para que essas organizações se favoreçam com um uso político direcionado a defesa de seus interesses e ampliando possibilidades de mobilização,

\footnotetext{
${ }^{4}$ A iniciativa surgiu no final de 2004, como parte de uma campanha maior, intitulada: “Onde você guarda o seu racismo?”, desenvolvida por 40 ONGs brasileiras.
} 
articulação, através da disseminação de temas e causas. É nesse sentido que corroboramos com a ideia de que:

Ás novas tecnologias de comunicação, têm-se atribuído a importância de instrumento político para movimentos sociais e organizações da sociedade civil. Além de cunhar novos tipos de relações sociais e tornar as informações mais acessíveis, as novas tecnologias estariam alterando as estruturas de poder, derrubando fronteiras temporais, geográficas, nacionais, sociais e culturais, para a criação de uma esfera pública transnacional. (MARZOCHI, 2000, p. 04).

Assim, consideram-se as ideias de Aguiar (2010) de que a Internet possibilitou diferentes formas de produção e organização das comunidades sociais, democratizou a informação, favoreceu a reorganização, a inclusão de movimentos sociais, das ONGs e das diversas identidades.

O uso da Internet se soma à produção de publicações, banners, folders relações com a mídia, não somente como estratégia de potencializar a comunicação interna através de $e$ mails, chats, etc., mas como mecanismo de visibilidade, distribuição de conteúdos, e principalmente canal de fomento à participação por uma camada mais ampla da sociedade, que vai para além dos seus públicos. O uso eficiente da Internet pelas ONGs vem assim ampliar no âmbito online, o desenvolvimento de políticas de comunicação tradicionais e o engajamento civil já presentes por essa esfera da sociedade civil.

Na perspectiva da apropriação do ciberespaço por ONGs, concorda-se que é importante

reconhecer espaços novos na arena virtual, em absoluto, significa subordinar as batalhas políticas ao avanço tecnológico, ou ainda aceitar impulsos voluntaristas que subestimam mediações sociais e mecanismos clássicos de representação política. (...) É no território físico, socialmente vivenciado, que se travam e se travarão as lutas decisivas por uma outra comunicação e um outro mundo possíveis (MORAES, 2007, p. 22).

Nesse sentido, a utilização da Internet passa a ser incrementada pelas ONGs, superando a compreensão inicial de otimização de recursos e velocidade como principais vantagens, e aproveitando dos ambientes e meios disponíveis no cyberespaço para ampliar alternativas de interação, enquanto possibilidade de "participação ativa do beneficiário de uma transação de informação” (LÉVY, 1999, p.77).

Nessa perspectiva Lopes (2005) reflete que “essa diferenciação da velocidade com que um ou outro tipo de organização faz para se apropriar da Internet, tem, entre outras razões, 
relação com a missão e o foco de cada segmento organizacional e as condições econômicas e financeiras para esse investimento” (LOPES, 2005, p. 60).

O caminho feito por tais organizações, muitas vezes, com base em suas práticas, é de desenvolver produtos de comunicação que, ao mesmo tempo, favoreçam a ação junto a seus públicos, potencializem e qualifiquem sua atuação, e proporcionem uma publicização da identidade institucional e das causas por elas defendidas para a sociedade em geral.

A partir desses pontos de vista, pode-se pensar que o engajamento político, através das pontencialidades que oferece as TICs, pode estar mais próximo, menos convencionalmente organizado e mais propenso a ser definido em termos de lutas pela evolução de noções de direito, moral e valores de vida. E é cada vez mais provável que o engajamento possa ocorrer tanto a nível local e global sem, ou com menor participação de instituições tradicionais do governo. Nesta perspectiva, as formas em que a comunicação se organiza, não só está mudando, mas exige novos conceitos e métodos de estudo (BENNETT, 1998; GIDDENS, 1991; INGLEHART, 1997; SCHUDSON, 1998).

Este artigo não traz em sua proposta avaliar se ocorre ou não engajamento cívico através dos espaços virtuais das ONGs estudadas. A perspectiva é mais simples. Através do conhecimento do modo como se estruturam os canais de informação e comunicação online das ONGs refletir se a Internet pode se configurar como uma alternativa para o engajamento cívico dessas organizações.

Para a realização dessa pesquisa, pautamo-nos em uma amostragem de 24 organizações não governamentais afiliadas à Associação Brasileira de ONGs, $\mathrm{ABONG}^{5}$ e identificadas no site da mencionada associação. A escolha por esse critério como principal, deu-se por serem tais entidades, dotadas de um perfil voltado para o comprometimento com as lutas no campo da promoção e da defesa de direitos, numa relação com um processo popular transformador e/ou voltado para ações de desenvolvimento.

\footnotetext{
${ }^{5}$ AATR-BA - Associação de Advogados de Trabalhadores Rurais no Estado da Bahia; AESOS - Associação Educacional Sons no Silêncio; AVANTE - Avante Qualidade, Educação e Vida; CAA - Centro de Assessoria do Assuruá; CEADE - Centro Ecumênico de Apoio ao DesenvolvimentoCEAS-BA - Centro de Estudos e Ação Social; CECUP - Centro de Educação e Cultura Popular; CEDECA-BA - Centro de Defesa da Criança e do Adolescente Yves de Roussan; CERMO - Centro Educacional de Entidades Reunidas; CESE - Coordenadoria Ecumênica de ServiçoCHAME - Centro Humanitário de Apoio à Mulher; CIEG - Centro Interdisciplinar de Estudos Grupais Enrique Pichon-Rivière; CIPÓ - CIPÓ Comunicação Interativa; CJP-SALVADOR - Comissão de Justiça e Paz de Salvador; CRIA - Centro de Referência Integral de AdolescentesELO - Elo - Ligação e Organização; FUNDIFRAN - Fundação de Desenvolvimento Integrado do São Francisco; GAMBA - Grupo Ambientalista da Bahia; GAPA-BA - Grupo de Apoio à Prevenção à Aids da Bahia; IPÊTERRAS - Instituto de Permacultura em Terras Secas; IRPAA - Instituto Regional da Pequena Agropecuária Apropriada; MOC Movimento de Organização Comunitária; SASOP - Serviço de Assessoria a Organizações Populares Rurais; VIDA BRASIL-B
} 
Com base nessas reflexões, e em diálogo com o conteúdo que integrou o campo teórico desse estudo, a pesquisa empírica utilizou elementos quantitativos e qualitativos em sua execução. No contato direto com os ambientes virtuais das ONGs pesquisadas, contou-se com a observação sistemática, não-participante e individual, que percebeu os seguintes aspectos: existência de site oficial; presença de links para redes sociais e/ou blogs institucionais, existência de espaços para interação com o internauta no site oficial e elementos que identifiquem periodicidade de atualização nos sites. Foi percebida também a natureza e a diversidade de conteúdos dos sites (principalmente contrapondo - dados e informações sobre a organização e sua atuação, e informações mais amplas no que se refere ao tema trabalhado (legislações, notícias, vídeos, informes, etc.)

Essas informações foram organizadas por instituição, a partir da construção de instrumentais que contemplaram a construção de indicadores específicos aos objetivos da pesquisa, tais como: tipo de ambiente virtual, fonte de informação, tipo de produto disseminado, conteúdo e observações, além do referencial de temporalidade (quando possível, periodicidade de postagem), possibilidades de participação oferecidas, entre outros aspectos, a serem agregados no decorrer dos estudos.

\section{CONSIDERAÇÕES}

A amostragem pautada em 28 organizações não governamentais afiliadas à Associação Brasileira de ONGs. Às afiliadas da ABONG, na Bahia um total de 57\% das organizações, no estado dispõem de espaços online oficiais em funcionamento ${ }^{6}$ (considerado o período da pesquisa) ${ }^{7}$, em contrapartida, um porcentagem alto de 21,43\% tem o domínio de site, mas esses encontram-se fora do ar, sem nenhum tipo de justificativa e o mesmo percentual não tem nenhum indicativo de referência na internet.

Em relação aos tipos de espaços disponibilizados oficialmente na Internet pelas ONGs, tem-se que $68,75 \%$ desses são websites, ao passo que 31,25\% das organizações utilizam-se do recurso do blog.

Do ponto de vista de elementos que ampliem o contingente informacional e interativo da organização no ciberespaço, foi possível perceber que $18,75 \%$ das entidades pesquisadas mantêm em seus sites links para blogs e também para redes sociais distintas (sendo as mais freqüentes - Facebook, YouTube e Twitter).

\footnotetext{
${ }^{6}$ Estamos considerando espaços oficiais sites, portais ou blogs apontados no site da ABONG, como referência virtual de cada instituição.

${ }^{7}$ Dezembro de 2010 e janeiro 2011.
} 
No próprio site, um percentual de 31,25\% garantiu espaços para interatividade com internautas no próprio site, e independente da manutenção de redes, blogs, ou outros mecanismos que favoreçam um tipo de interação mais fluida. A maioria desses instrumentos era o conhecido espaço de "fale conosco", para que o internauta possa enviar mensagens de dúvidas, críticas, elogios, ou estabelecer um contato mais direto com a equipe institucional, mas é preciso pontuar também o registro de enquetes de opinião, normalmente relacionadas às causas defendidas pelas instituições.

Sobre assuntos e temas, é preciso salientar, em um olhar mais qualitativo, que aos conteúdos pautados nos sites foram divididos em dois aspectos macro. Primeiramente o que seria conteúdo institucional, ou seja, aquele que se refere à constituição da identidade institucional, incluindo-se aspectos como: histórico, missão, projetos, equipe, fotos, vídeos produzidos em decorrência da intervenção, etc. E como segunda vertente considerou-se o que chamamos de “conteúdo temático ampliado’, um tipo de conteúdo que se refere aos temas trabalhados pela instituição, mas que extrapola seu âmbito de intervenção, referenciando-se a publicações, textos produzidos fora da organização, download para legislações, dissertações, teses ou outros trabalhos de pesquisa, e que tendam ao propósito ampliar o grau de conhecimento dos usuários da Internet sobre o tema de forma geral.

No entanto, em relação a esses quesitos, o que foi possível perceber foi que a maioria das organizações, 93,75\% disponibiliza conteúdo institucional, enquanto apenas 6,25\% das organizações preocupam-se exclusivamente com um conteúdo relacionado ao tema, todavia sem fazer referência às práticas institucionais. Desse total, $60 \%$ das organizações que disponibiliza conteúdo sobre a organização, buscam compatibilizar isso com conteúdos e informações de um contexto mais amplo, relacionado aos temas trabalhados, conforme exemplificamos na conceituação dessas categorias.

Pensando que a utilização de espaços na Internet pelas ONGs pode ser uma estratégia de fortalecimento do engajamento cívico fomentado por tais organizações, tanto maior forem às oportunidades de participação e as informações disponibilizadas acerca do tema trabalhado, para além do contexto específico da ação institucional, pelos resultados observados, as ONGs afiliadas da ABONG na Bahia oferecem exímias possibilidades de fomentar o engajamento cívico e possivelmente apenas alente a hipótese do reforço do engajamento, daqueles já interessados.

Em um cômputo geral, os resultados apontam para uma pouca utilização de espaços na Internet de uma forma geral. Dentre as ONGs estudadas que privilegiam as estratégias de 
comunicação virtual, é mais comum que se encontrem sites oficiais institucionais, ainda com poucos índices de criação de canais paralelos que promovam algum tipo de participação.

Analisando os resultados é possível fazer algumas considerações. As ONGs ainda precisam criar condições de ampliar as possibilidades de utilização de recurso da Internet, e buscar uma maior compreensão sobre as alternativas de interatividade e participação que o cyberespaço proporciona para a promoção de suas causas.

Existem espaços de baixo custo que podem promover uma ampliação das discussões promovidas por tais organizações e que carecem de ser melhor aproveitados, haja visto as redes sociais, os blogs ou a criação de fóruns.

Desta maneira, e importante para o estabelecimento de relações de confiança e engajamento cívico, que os conteúdos sejam definidos de forma a se pensar para além da visibilização institucional, mas que tenham um caráter político pedagógico, que venha a instrumentalizar o internauta em busca de informações, sobre questões relevantes ligadas aos temas trabalhados.

O estudo suscita aprofundamentos e continuidade, na perspectiva de perceber a ressonância dos conteúdos disponiblizados nos espaços da Internet pelas ONGs, para a constituição de relações de confiança, sensibilização da opinião pública e promoção de engajamento cívico, ademais da ampliação da análise as ONGs de outros estados.

De forma geral, a pesquisa permitiu sinalizar que a centralidade da informação disponibilizada pelas Organizações, ainda reside nas práticas institucionais e que há poucas ferramentas de participação, o que torna a utilização da Internet pela ONGs, uma alternativa pouco explorada para fomentar o engajamento cívico. Seja no ambiente online ou offline é preciso o desenvolvimento de políticas e estratégias de comunicação adequadas que considerem, por exemplo, a diversidade de temas e públicos, e o conhecimento de ferramentas apropriadas, para que o engajamento cívico seja então uma realidade. 


\section{REFERÊNCIAS}

ARATO A. e COHEN J. Sociedade Civil e Teoria Social. Sociedade Civil e Democratização. Ed. Del Rey. Belo Horizonte. 1994.

ARMANI, Domingos. Breve Mapa do Contexto das ONGs Brasileiras, 1999. Disponível em: www.abong.org.br. Acesso em: 10 jun. 2010.

BOBBIO, Norberto. Dicionário de Política. Brasília, Editora UnB, 1999.

CHIZZOTTI, Antonio. Pesquisa em Ciências Humanas e Sociais. $2^{\mathrm{a}}$ Ed. São Paulo, Cortez, 1995. (Biblioteca da Educação Série 1. Escola v.16).

CARVALHO, Marcos. Planejamento urbano e participação em salvador os meios de comunicação no pddu 2008. Dissertação de Mestrado (versão preliminar). Departamento de Arquitetura. UFBA. O autor. Salvador, BA, 2010.

GRAMSCI, A. Cadernos do cárcere: os intelectuais, o princípio educativo, jornalismo. Rio de Janeiro: Civilização Brasileira, 2000a. v. 2.

GOHN, Maria da Glória. ONGs, Sem Terra e Cidadania. $3^{\text {a }}$ Ed. São Paulo, Cortez, 2003.

JACOBI, Pedro. Movimentos Sociais e Políticas Públicas. $2^{\mathrm{a}}$ Ed. São Paulo, Cortez, 1993.

LEMOS, André; CUNHA, Paulo (orgs). Olhares sobre a Cybercultura. Porto Alegre, 2003, p. 11-23.

LÉVY, Pierre. Cybercultura. São Paulo, Ed. 34, 1999 (Coleção Trans).

MACHADO, Jorge Alberto S. Ativismo em Rede e Conexões Identitárias, novas perspectivas para os movimentos sociais. Sociologias, Porto Alegre, ano 09, $\mathrm{n}^{\mathbf{0}} 18$, jul./dez. 2007, p.248-285. Disponível em: http://seer.ufrgs.br/index.php/sociologias/article/view/5657/3256. Acesso em: 01 set. 2010.

MATOS, Heloíza. Capital Social e Comunicação - interfaces e articulações. São Paulo, Summus, 2009.

MENESCAL, Andrea Koury. História e Gênese das Organizações Não governamentais. In: SIGNORE, Hebe Gonçalves. (org.) Organizações Não Governamentais. Solução ou Problema? São Paulo, Estação Liberdade, 1996.

MONTAÑO, Carlos. Terceiro Setor e Questão Social: crítica ao padrão emergente de intervenção social. São Paulo, Cortez, 2002.

PINHEIRO, Paulo Sérgio. Apresentação. In: AVRITZER, Leonardo (coord.) Sociedade civil e democratização. Belo Horizonte, Del, 1994. 
RAMOS, Murilo César. Sobre a importância de repensar e renovar a sidéia de dosciedade cvil. IN: RAMOS, Murilo César. SANTOS, Suzi. Políticas de comunicação bases teóricas e praticas. São Paulo. Paullus, 2007.

RIBEIRO, Sâmbara Paula Francelino. Parceria: Os caminhos da relação entre o Poder Público Estatal e as ONGs. Dissertação (Mestrado em Serviço Social). Recife, Universidade Federal de Pernambuco, 2000.

SILVA, Edna Lúcia da. Metodologia da pesquisa e elaboração de dissertação. $3^{\mathrm{a}}$ Ed. Florianópolis, Laboratório de Ensino a Distância da UFSC, 2001.

SOUZA, Carlos Alberto Lopes de. ONGs e Internet: da ação educativa ao lugar no cyberespaço. Tese de Doutorado - PUC - SP. Disponível em: http://www.dhnet.org.br/dados/teses/a_pdf/tese_1dh_carlinhos_dhnet.pdf. Acesso em: 28 ago. 2010.

Original recebido em: 30/04/2013

Aceito para a publicação em: 20/07/2013

Raquel G. de Oliveira

Doutora e Mestre em Comunicação e Jornalismo pela Universidad Autónoma de Barcelona.

Pela mesma universidade realizou especialização em Ciberjornalismo e Linguagem, e uma pós graduação em Grafismo Informativo e Documental. Estudos que complementaram sua formação em Comunicação Social - Relações Públicas, pela Pontifícia Universidade Católica do Paraná.

Luciana de F. P. Santos

Mestranda em Gestão Social e Desenvolvimento pela UFBA, especialista em Movimentos Sociais e Democracia Participativa (UFMG) e Assistente Social, (UFPE). 